\title{
Non-Financial Reporting in Italian SMEs: An Exploratory Study on Strategic and Cultural Motivations
}

\author{
Donato Calace ${ }^{1}$ \\ ${ }^{1}$ LUM University, Casamassima, Italy \\ Correspondence: Donato Calace, Ph.D. Student, LUM University, S.S. $100 \mathrm{~km} 18$ Casamassima, BA 70010, Italy. \\ Tel: 39-80-697-8111. E-mail: calace@lum.it \\ Received: March 18, 2014 \\ Accepted: April 15, 2014 \\ Online Published: April 30, 2014 \\ doi:10.5430/ijba.v5n3p34 \\ URL: http://dx.doi.org/10.5430/ijba.v5n3p34
}

\begin{abstract}
In the last years, a broadening process of companies' responsibilities has taken place. Institutions, customers, authorities and the general public opinion expect companies to behave in an ethical way, including social and environmental elements beside economic ones in their decision-making processes and goal setting. In this context, non-financial reporting has become a critical activity to manage the dialogue with stakeholders. Indeed, corporate social disclosure (CSD) represents the most direct expression of companies' commitment on social and environmental grounds. Through CSD, large and multinational companies succeed in improving their legitimacy, stakeholder's trust, reputation, image and reliability, creating a set of intangible assets that eventually increase their economic performance. Shifting to SME level, the involved dynamics significantly change, mainly because of the limited visibility of small and medium firms compared to large and multinational ones. This working paper intends to offer an insight on strategic and cultural motivations that drive SME non-financial reporting. Through a qualitative approach based on a pilot case study, I start to shed light on the under researched world of SME non-financial reporting, in particular addressing to Hofstede's national culture framework, in view of a future cross-country extension of this study.
\end{abstract}

Keywords: corporate social disclosure, Hofstede cultural dimensions, SMEs

\section{Introduction}

The definitions of business accountability and success have broadened: today, firms are called to achieve environmental and social goals, as well as economic ones, raising a triple bottom line approach (Elkington, 1997). Following such "sustainability imperative" (Lubin \& Esty, 2010), stakeholders ask companies to voluntarily include social and environmental elements in their decision-making and strategic processes and to be acknowledged about their non-financial performance. As "the level of CSR activities of the firms is made known to public only through the disclosures" (Kavitha \& Anita, 2011, p. 45), disclosing non-financial information has become a critical activity.

CSR activities and reporting imply going beyond legal requirements and engaging in voluntary actions (McWilliams, Siegel, \& Wright, 2006). It is a managerial task to determine the definition and the boundaries of company accountability, defined as the duty to provide an account or reckoning of those actions for which one is held responsible (Gray, Owen, \& Adams, 1996), thereby affecting the amount of sustainability disclosures reported to stakeholders (Michelon \& Parbonetti, 2010). Companies have a plenty of ways to communicate such information to stakeholders, e.g. the annual report, through the so-called "silent social account" (Gray, 1997), special publications, documents or reports, and socially orientated advertising (Kavitha \& Anita, 2011). Relevant research (Michelon \& Parbonetti, 2010) points out that sustainability reports are on average the preferred mean to disclose non-financial data. Corporate social disclosure (CSD) represents the most direct expression of firms' CSR and reporting-based analyses are the correct way towards the comprehension of what can be considered a socially responsible behaviour (Perrini, 2005). Indeed, today more than two-thirds of the Fortune Global 500 companies issue a non-financial report (LeBlanc, 2012), showing a growing trend that is not prompted by contingent and temporary forces (Kolk, 2003). Corporate responsibility reporting is also growing in emerging economies, in particular in the Asia Pacific area and Latin America (KPMG, 2013). The gap between leading and lagging industry sectors is narrowing too, converting reporting in a diffused and cross-sectorial managerial practice (KPMG, 2013). 
Large firms motivate non-financial reporting mainly through cost-benefit assessment (Spence \& Gray, 2007). Indeed, they can leverage on intangible assets, such as legitimacy, reputation, reliability, built on the image they convey to stakeholders. If there are still uncertainties regarding corporate social disclosure business case, as the relationship between sustainability disclosures and sustainable performance is still unclear (Ullman, 1985; Clarkson, Li, Richardson, \& Vasvari, 2007) because of methodological and measurement weaknesses, researchers definitely agree on the existence of a stakeholder case (Perrini, Russo, Tencati, \& Vurro, 2011).

Yet, this reasoning cannot be extended to SMEs. Indeed, small and medium businesses are not "little big firms" (Tilley, 2000), "because of the intrinsic differences between large firms and SMEs" (Russo \& Perrini, 2010, p. 209). For this reason, this working paper intends to analyze non-financial reporting dynamics, motivations and effects in SMEs. In particular, I chose a qualitative approach based on multiple-case studies and recorded semi-structured interviews (Yin, 2003), as CSD in SMEs is an almost unexplored domain (Chen \& Bouvain, 2009) and such kind of methodology is particularly suitable where theory building is needed (Eisenhardt \& Graebner, 2007).

In the next section, I present relevant literature regarding CSR and especially non-financial reporting in SMEs. Particularly, I focus on cultural dimensions affecting the dynamics of corporate social disclosure, depicting how and why they influence CSD. Addressing Hofstede (Hofstede, Hofstede, \& Minkov, 2010) national cultures framework, I predict how culture drives non-financial reporting in Italian SMEs. In the methodology section, I provide details regarding the research protocol adopted to choose the business case and make the interview. Then, I discuss the consistency of the evidences from the business case with the predictions coming from Hofstede's dimensions of national culture. In the end, I draw the conclusions and present the first implications for academia and management, and especially the further work I intend to do on the basis of this working paper.

\section{Literature Review}

\subsection{CSR and Non-financial Reporting in SMEs}

Corporate social disclosure, that is "the process of providing information designed to discharge social accountability" (Sutantoputra, 2009, p. 36), is commonly conceived as an activity belonging to the broader field of Corporate Social Responsibility. CSR and its sister-concepts, like corporate citizenship (Mirvis \& Googins, 2006), sustainable entrepreneurship (Schaltegger \& Wagner, 2011), triple bottom line (Elkington, 1997), corporate sustainability (Dyllick \& Hockerts, 2002) describe why and how firms are called to respond for the environmental and social consequences of their conduct, providing explanations at institutional, organizational and individual level of analysis (Aguinis \& Glavas, 2012). Mirvis and Googins (2006) include corporate "public reporting, assurance and full disclosure" as activities carried out in the most advanced stages of corporate citizenship in the "transparency" dimension, one of the seven fundamental dimensions describing this concept. Spiller (2000) includes "open communication with financial community", "reporting to provide a picture of the company's performance" and "disseminate comprehensive and clear information" in his comprehensive list of sixty business practices that companies can adopt to address business ethics and CSR. Perrini (2005, p.611) claims that "non-financial reporting has grown up together with the evolution of the concept of CSR, relying on the assumption that the former can be derived from the latter, thus meaning "social responsibility" in the sense that the company is held accountable for its actions".

Most of literature has grounded the adoption of CSR-oriented strategies in the stakeholder theory (Searcy, 2012). For this reason, corporate social disclosure finds its main theoretical antecedent referring to Freeman's (1984) original contribution: "the disclosure of financial, social and environmental information is part of the dialogue between a company and its stakeholders and it provides information on a company's activities that legitimize its behavior, educate and inform, and change perceptions and expectations" (Michelon \& Parbonetti, 2010, p. 478). CSD allows stakeholders to look at a company through the eyes of management, shaping their perceptions and expectations regarding company behavior, eventually driving their consume and investment decisions (Perrini, Russo, Tencati, \& Vurro, 2011).

However, the effectiveness of this theoretical framework in explaining CSR at the SME level is questioned. As Russo and Tencati (2009, p.339) suggest: "theoretical models of the relationship between large firms and CSR, such as the stakeholder theory, do not necessarily explain the CSR-SME relationship, since researchers examining CSR in large corporations may not find it possible to generalize their findings to SMEs". A stakeholder view of SMEs can work only if small and medium businesses idiosyncrasies are duly taken into account (Russo \& Perrini, 2010). Considering the specific non-financial reporting practice, in large firms, the decision to issue a non-financial report is in most cases motivated through economic thinking: social and environmental reporting deliver benefits to a range of stakeholders while serving to enhance shareholder value (Spence \& Gray, 2007), establishing a sort of "stakeholder 
case" (Perrini, Russo, Tencati, \& Vurro, 2011). According to this view, CSD generates and enhances organizational legitimacy, demonstrating that a firm shares the same value system of the wider community (Michelon \& Parbonetti, 2010), trust and reputation (Lamberti \& Lettieri, 2009), moving from a "trust me" approach to a "tell me" one (Perrini, 2005), shareholder value creation alignment with social value creation (Chatterji \& Levine, 2006), reliability, transparency and brand positioning (Perrini, Russo, Tencati, \& Vurro, 2011). This is true especially for multinational, listed firms. Visibly, at SMEs level the scenario is quite different. Not by chance, there is a major size-effect in the practice of non-financial reporting: as explained by Brown, de Jong, \& Levy (2009), in recent years large multinational enterprises have dominated sustainability reporting. A number of reason support the size-disclosure relationship. Firstly, larger firms are more political visible and often become the "focal point" of broader wars against social and environmental injustices (Chatterji \& Levine, 2006). As a result, big companies try to reduce this pressure by various measures, like non-financial reporting (Watts \& Zimmerman, 1986). Secondly, bigger firms may enjoy economies of scale and bear lower information production costs (Foster, 1986), or lower costs of competitive disadvantage resulting from disclosing corporate information (Meek, Roberts, \& Gray, 1995). As a result, the extent of CSR reporting drops off rapidly as the size of the company decreases (Chen \& Bouvain, 2009).

Consequently, CSR in SMEs and especially SME social disclosure need to be grounded in a new theoretical framework. First, the reduced size of SMEs makes them more subject to institutional pressure, limiting their bargaining and lobbying power. In this sense, the institutional and neo-institutional theories (DiMaggio \& Powell, 1983; Selznick, 1948; Scott, 2001) offer a valid reference to explain how the national and the industry institutional environments affect the SME-CSR relationship. Social, economic, and political factors form an institutional structure of a particular environment, which, through the so-called isomorphism, induces firms to assume specific behaviors, like the disclosure of non-financial information, or, more in general, a social responsible attitude. Evidently, institutional pressures affect large firms too, but Graafland, Van de Ven and Stoffele (2003) advance that four main motivations explain difference in the reactions: visibility, adequate communication instruments, economies of scale and competitiveness. Second, SMEs are closely and firmly linked to the local communities where they operate (Russo \& Tencati, 2009): "small businesses need such relations with the community to survive, whereas, in general, large firms do not. Therefore, it is the community that wants CSR from small businesses, and as a consequence small businesses pursue CSR." (Russo \& Perrini, 2010, p. 211). The social capital theory can further describe this relationship. Putnam $(2000$, p.19) gives this notion of social capital: "whereas physical capital refers to physical objects and human capital refers to the properties of individuals, social capital refers to connections among individuals - social networks and the norms of reciprocity and trustworthiness that arise from them that can improve the efficiency of society by facilitating co-ordinated actions". Ethical issues, such as openness and trust, religious-based ethics, selected relationships with suppliers, honest dealings with employees, drive SMEs development, granting them with the license to operate in local communities (Russo \& Tencati, 2009). In this way, "CSR is the outcome of the relational accumulating process through which SMEs build their social capital" (Russo \& Perrini, 2010, p. 207-208). So while the stakeholder theory is more focused on concluding transactions with stakeholders, the social capital theory stresses relationship management. Third, in SMEs the role of the entrepreneur, with his capacities, knowledge and values, is central in shaping firm's strategy and practices. Only a sustainability-committed entrepreneur can balance environmental, economic and social impacts of the activity, seizing sustainable business opportunities and acting upon them in a proactive way (Spence, Gherib, \& Biwolé, 2011). Sustainable entrepreneurship theory formalizes this notions, as described by Schaltegger and Wagner (2011, p. 226): "an innovative, market-oriented and personality driven form of creating economic and societal value by means of break-through environmentally or socially beneficial market or institutional innovations". According to this view, sustainable SMEs rely "on the the personal initiative and skills of the entrepreneurial person or team to realize large-scale market success and societal change with environmental or societal innovations" (Schaltegger \& Wagner, 2011, p. 226), rather than formalized procedures, CSR tools and management systems.

Indeed, empirical evidence shows that SMEs lack CSR formal tools, such as ethical codes, standards, certifications and reports, even if they carry out several initiatives, especially those significantly affecting the bottom line (e.g. reduction of resource consumption and waste reciclying) and those linked to improving legitimacy and reputation within local communities (Russo \& Tencati, 2009). This leads to an informal - or "sunken", or "silent" - (Russo \& Tencati, 2009) and implicit (Matten \& Moon, 2008) approach to CSR, according to which CSR-related practices represent the reaction to specific pressures of the external environment and they are rarely and poorly communicated to stakeholders. Often, SMEs are even implementing responsible actions without realizing that they are part of the wider sustainability framework ("blind" CSR). The main reason behind this lies in that CSR formal practices require 
investments of time, resources and energy that SMEs cannot afford. The risk of potential loss originating from the failure to adopt a formal CSR tool is greater for SMEs rather than large firms, due to their limited resources. Moreover, corporate social responsibility is a complex domain, endowed with pluralistic goals, ambiguity, uncertainty, and context dominance (Searcy, 2009). It requires multidisciplinary competencies, as well as the inclusion of stakeholders' panels in its processes, creating the opposition of different mindsets (O'Dwyer, 2011). As a result, "in many corporations, people are simply not equipped to effectively pursue a commitment toward corporate sustainability" (Searcy, 2012, p. 240), and a lack of these capabilities can represent a serious impediment for the diffusion of sustainability practices, like non-financial reporting (Perego \& Kolk, 2012). Finally, the very nature and the main advantage of SMEs in relation to larger firms is flexibility, achieved through weak formalization and intuitive managerial style (Julien, 1993).

\subsection{Culture, CSR Practices and Corporate Social Disclosure}

The proposed theoretical review suggests that CSR practices and in particular CSD adoption in SMEs follow a different logic from the cost-benefit assessment that features non-financial reporting in larger firms. Although addressing different issues, the three theoretical frameworks describing the CSR-SME relationship share a common antecedent: culture, as they all relate to the system of value and beliefs that drive the activity of SMEs. "Culture influences moral values, which one would expect in turn to influence at least the issues which companies select as being worthy of report" (Chen \& Bouvain, 2009, p. 302). According to Hofstede (1983), culture is the collective programming of the mind, which distinguishes the members of one group or category of people from another. Thus, it is learned through a process of social construction within the social environment (nations, families, organizations) and not inherited. Hofstede, Neuijen, Ohayv, and Sanders (1990), observed four mutually exclusive and reasonably comprehensive manifestations of culture: heroes, symbols, rituals and values. The first three are visible to observer, as they describe situations as they are and relate to words, gestures, pictures or objects (symbols), real or imaginary people (heroes), behaviors and activities (rituals) that carry a particular and precise meaning within a social context. The latter one is manifested in behaviors, and relates to situations as they should be. Values system is built during early years of childhood, through an unconscious process which determines the differences among national cultures.

Thus, culture is one of the most important determinants in national ethics, and empirical evidence found it to be significant in explaining ethical attitudes, ethical sensitivity, value system, ethics judgments, ethical decision-making and ethical perception (Ho, Wang, \& Vitell, 2012). Consequently, despite the normative process behind the development of reporting frameworks assumes the existence of a set of universal values that can be applied to all business worldwide (Logsdon \& Wood, 2005), as organizations providing standards and guidelines are international (e.g. GRI, UN, ISO), significant national differences remain in CSR reporting. In particular, the country where the business is headquartered determines the nature and extent of non-financial disclosure (Chen \& Bouvain, 2009). Matten and Moon (2008) show that European CSR practices are more implicit compared to US ones. This is because CSR is a socially constructed concept, and thus cannot be universally defined (Dahlsrud, 2008): the culture of the nation and the culture of the firm too significantly affect the development and application of CSR within individual organizations (Gjølberg, 2009).

Hofstede (1983) states that all national cultures deal with four basic problems: social inequality, including the relationship with authority; the relationship between the individual and the group; the social implications of having been born as a boy or a girl; ways of dealing with uncertainty and risk. The way countries find answers to these problems determine their cultural dimensions, which are measurable aspects of culture that allow comparison between nations. The original four-dimensional model of cultural differences includes four dimensions: power distance, collectivism versus individualism, femininity versus masculinity and uncertainty avoidance. Other studies addressed the national cultures topic, like the GLOBE project (House, Javidan, Hanges, \& Dorfman, 2002), but they are built on Hofstede's original contribution, as it accounts for much of the cultural variability and has found wide application in different disciplines (Ho, Wang, \& Vitell, 2012).

In the following part, I provide the Hofstede Centre (2013) description of each cultural dimensions, showing their link with CSR dimension and practices provided by literature:

\section{Power distance (PDI)}

"This dimension expresses the degree to which the less powerful members of a society accept and expect that power is distributed unequally. The fundamental issue here is how a society handles inequalities among people. People in societies exhibiting a large degree of power distance accept a hierarchical order in which everybody has a place and which needs no further justification. In societies with low power distance, people strive to equalize the distribution of power and demand justification for inequalities of power". Cohen, Pant and Sharp (1996) show that countries with an 
high PDI score are more likely to accept questionable firms' behaviors, consistently with Ringov and Zollo (2007) findings. On the other hand, Ho, Wang and Vitell (2012) claim that in a structured environment, endowed with high collectivism, high uncertainty avoidance and high masculinity, higher PDI is significantly associated with better corporate social performance, as questionable business practices against the collectivity are not tolerated. Leonidou, Kvasova, Leonidou and Chari (2013) suggest individuals in countries with high power distance tend to follow more formal rules, while in low PDI countries informal codes of ethics are preferred. Being CSR and CSD voluntary activities, based on non-compulsory practices, individuals and organizations with high PDI tend to ignore and underestimate them.

\section{Individualism versus Collectivism (IDV)}

"The high side of this dimension, called Individualism, can be defined as a preference for a loosely-knit social framework in which individuals are expected to take care of themselves and their immediate families only. Its opposite, Collectivism, represents a preference for a tightly-knit framework in society in which individuals can expect their relatives or members of a particular in-group to look after them in exchange for unquestioning loyalty. A society's position on this dimension is reflected in whether people's self-image is defined in terms of I or we". Apparently, a low IDV score should lead to a higher use of CSR practices, as collectivistic countries encourage social behavior that is determined by duty/obligation and business relationship are perceived in moral terms, like a family link (Leonidou, Kvasova, Leonidou, \& Chari, 2013). On the other hand, today western countries lead the CSR trend, while eastern countries (more collectivistic) lag behind. The common association between low IDV and high PDI may explain this situations, as collectivist countries are less likely to question what superiors and executives in the company are doing (Ho, Wang, \& Vitell, 2012). Moreover, companies introduce CSR practices and in particular non-financial disclosure to signal their sustainability commitment to stakeholders and to gain a differential competitive advantage (Porter \& Kramer, 2011): differentiation is not desirable in collectivistic countries, where harmony and omogeneity is preferred.

\section{Masculinity versus Femininity (MAS)}

"The masculinity side of this dimension represents a preference in society for achievement, heroism, assertiveness and material reward for success. Society at large is more competitive. Its opposite, femininity, stands for a preference for cooperation, modesty, caring for the weak and quality of life. Society at large is more consensus-oriented". Strong competitiveness, greed and individual achievements characterizing masculine societies are frequently cited as drivers of unethical behaviors (Ho, Wang, \& Vitell, 2012). In masculine countries, results and economic growth are the most important target: individuals and organizations achieve them with any means, even bypassing rules. Masculine society is more tolerant towards ethically questionable behaviors of individuals and organizations (Leonidou, Kvasova, Leonidou, \& Chari, 2013). Conversely, feminine societies value non-financial performance.

\section{Uncertainty avoidance (UAI)}

"The uncertainty avoidance dimension expresses the degree to which the members of a society feel uncomfortable with uncertainty and ambiguity. The fundamental issue here is how a society deals with the fact that the future can never be known: should we try to control the future or just let it happen? Countries exhibiting strong UAI maintain rigid codes of belief and behaviour and are intolerant of unorthodox behaviour and ideas. Weak UAI societies maintain a more relaxed attitude in which practice counts more than principles." High UAI reflects society law-abiding and rule-oriented behavior: norms and standards provide indications to limit risk and deal with uncertain situations. Therefore, unethical and risky behaviors are undesirable in these countries, where there are strict and binding regulations (Ho, Wang, \& Vitell, 2012). High uncertainty avoidance societies tend to question unethical standards and violations made by organizations to a greater degree (Vitell, Paolillo, \& Thomas, 2003) and accordingly have a greater need to be acknowledged on companies social and environmental issues.

\subsection{The Italian Context}

It is useful to present Italian cultural context in order to understand how cultural dimensions affect SMEs' corporate social disclosure. Considering Hofstede cultural dimensions, Italy shows a medium ranking in terms of power distance (50), thus it is "a society that believes that hierarchy should be respected and inequalities amongst people are acceptable. The different distribution of power justifies the fact that power holders have more benefits than the less powerful in society" (The Hofstede Centre, 2013). With a score of 76, Italy is an individualistic country: "for Italians having their own personal ideas and objectives in life is very motivating and the route to happiness is through personal fulfillment" (The Hofstede Centre, 2013). In masculinity dimension, Italy scores 70: "it is highly success oriented and driven. Children are taught from an early age that competition is good and to be a winner is important in 
one's life" (The Hofstede Centre, 2013). "Formality in Italian society is important and the Italian penal and civil code are complicated with clauses, codicils etc. In work terms high uncertainty avoidance results in large amounts of detailed planning." (The Hofstede Centre, 2013): Italy has an high score (76) in uncertainty avoidance.

Considering the resulting italian dominant culture, institutional pressure seems to be the main driver of CSR practices and CSD in Italy. The high score in UAI suggests that formal practices, like non-financial reporting, are desirable, because reduce risks and uncertainties. On the other hand, the high scores on IDV and MAS advance that social and environmental issues are not on the top of companies'agenda. Consequently, given the moderate-high score of PDI, companies are willing to adopt CSR practices if they are enforced or strongly advocated by legitimate institutions. Indeed, the combination of PDI, IDV and MAS scores indicates that companies would ignore or at least underrate commitment in CSR practices because they are voluntary. Albareda, Tencati, Lozano and Perrini (2006) identify italian CSR system in what they call the Agora model, as Italy has a more extensive, multi-stakeholder and multi-level approach compared to UK systemic, national government-centred and business-oriented approach. In Italy, the initiative of the public government supports CSR initiatives at national and regional level, and its action is always coordinated with different social groups and business actors (Habisc, Patelli, Pedrini, \& Schwartz, 2011). Accordingly, CSR practices in firms are a reaction to the institutional environment instead of a strategic decision, and remain in an implicit dimension (Matten \& Moon, 2008) as an informal commitment towards collective legitimate expectations. In Hall and Soskice (2001) classification of "varieties of capitalism", Italy has an ambiguous position between liberal market economies (like UK, US, Australia, Canada) and coordinated market economies (e.g. Austria, Belgium, Japan, Netherlands). Firms in the latter cluster face greater institutional pressure to behave in a socially responsible way from strong state regulation, collective industrial organizations, NGOs and other indipendent organizations (Campbell, 2006). Oppositely, companies operating in more liberal market economies have to satisfy investors and shareholders demands for information, including in particular non-financial one.

\section{Methodology}

In this paper, I propose a single case study methodology based on a recorded semi-structured interview (Yin, 2003) in order to verify if the above considerations regarding CSR practices in Italy can be extended to SMEs. Research underlines the persuasive power of a single case (Siggelkow, 2007) in particular if it is "unusually revelatory, an extreme exemplar, an opportunity for unusual research access" (Eisenhardt \& Graebner, 2007, p. 27). The proposed case follows the logic of theoretical sampling, as it is "particularly suitable for illuminating and extending relationships and logic among constructs" (Eisenhardt \& Graebner, 2007, p. 27).

In particular, I selected the company from Global Reporting Initiative (GRI) Sustainability Disclosure Database (Global Reporting Initiative, 2014), which provides non-financial reports and company data for firms submitting their non-financial reports. Today the GRI Sustainability Disclosure Database features more than 16000 reports issued by more than 5000 organizations, and the GRI itself is the most well-known and widely applied guideline for sustainability reporting and exhibits several features of an established institution, such as broad uptake and legitimacy (Brown, de Jong, \& Levy, 2009).

The research protocol followed this path: I created a list of potentially interesting SMEs based on the data reported in the GRI database. Then, I established a first contact with the company, in order to identify who had the responsibility of non-financial reporting activity and arrange an interview. In the proposed case, I interviewed the CSR Manager of the company. The interview lasted about 1 hour and regarded three main themes: CSR practices in the company, motivations and effects of the reporting activity, general opinions on CSR and social reporting. The questionnaire and the transcript of the interview are available in the annexes of this paper. The interview was held in Italian, then transcribed and submitted to the interviewee for review. Finally, I translated the text in English and had it checked by a professional translator. I triangulated the findings from the interview with information coming from the company non-financial report and from the website in order to increase the validity of the results. Interviews may lead to socially desirable answers (De Jong, Pieters, \& Fox, 2010). To avoid this bias, I communicated to the interviewee that the case study use general names, preventing the identification of the company, and there were no right or wrong answers (Leonidou, Kvasova, Leonidou, \& Chari, 2013).

\section{Results}

The analyzed company, named "Alfa" from this point, is an Italian private company limited by shares established in 1939. Its core business is the manufacture of crown corks, metal and plastic caps for the bottling industry. It is headquartered in the central-north part of Italy, in Emilia Romagna. Its activity is strongly export-driven: "Our production is mostly addressed to the international market. Indeed, more than the 50\% of our products is sold outside Europe. Our commercial network is international and speaks more than 20 different languages." (Alfa CSR 
Manager). According to UE (European Commission, 2013) classification, Alfa is a medium-sized firm, as it has less than $€ 50$ million as turnover and less than 250 employee. Alfa published its first non-financial report in 2011, following the GRI G3.1 Guidelines and achieving a "B" Application Level - The "Applications Levels" (AL) system assesses the grade of disclosure, giving a score that goes from $\mathrm{C}$ (minimum disclosure) to A (full disclosure). Report makers self-declare their Application Level, and, in addition, they can have their self-declaration externally assured by a third party (receiving a "+" to their AL) and/or request the GRI to check the self-declaration (Global Reporting Initiative, 2011). In 2012, Alfa published a second non-financial report, increasing its disclosure by 20 indicators. The 2013 sustainability report is currently in development. Non-financial reporting is not the only CSR practice: Alfa has a Code of Ethics, an Environmental Policy document and the ISO 14001 Certificate. According to Spence, Gherib and Biwolé (2011) classification of SMEs according to their CSR, Alfa belongs to the "committed" profile.

Alfa considers CSR as a dimension intimately linked to their activity: "Ethical values, enthused by true sustainability, inspire our business approach, they are native, inborn in it and people just follow them but are not aware of them". Part of these values derives directly from their business logic: "Some topics, linked to environmental sustainability and resource saving, were a central point in our business. The steel industry is strongly endowed with the ideas of restoring and recycling raw materials". Recycling and waste saving is not a value per-se or because it protects the environment, but because allows cost savings, which are vital in a high-competitive industry: the masculine side of culture is evident in this statement. This logic is manifest also in the fact that CSR is considered a way to create, maintain and strengthen relationship along the supply chain: "Many suppliers from our supply chain approached CSR topics just like us: they are starting to formalize and report their existent commitment. Most of them come from Europe, so they are in an extremely competitive environment, where the level of attention to these themes is very high. On the other side, Far-East suppliers are starting to pay some attention to these dimensions and I think that in the following years there will be a major evolution in this sense. Our commercial partners and clients share a high level of responsiveness to CSR. They are in direct contact with the final market, which is demanding in this direction. Our commitment has certainly valued our company". Contrary to the predictions, institutional pressure plays a more limited role than expected in CSR practices commitment: "local and international authorities have a strong influence on our business. With our reporting initiative, we show a proactive and sensitive approach towards environmental impacts, workplace conditions, and commercial relationships. During assessments, we can thus provide data in a clear and structured way, improving our corporate image and legitimacy". Accordingly with the social capital theory, Alfa pays attention to the local community: "Local communities can benefit too. Volunteering and philanthropic initiatives raise the awareness that the company is interacting in a positive way in its context. We made the report available for download on our company website, as a way to guarantee the diffusion of the information."

Addressing the specific CSD topic, market and supply chain logic are the most important antecedent: "We want to promote our social responsibility commitment along the supply chain, from our suppliers to the final market, which is getting more and more receptive towards these topics. Manufacturing and trading world is gaining consciousness of CSR themes, and we are trying to embrace this philosophy structuring the activities that head in this direction". Coherently with the individualistic trait of the Italian dominant culture, reporting is considered a chance to differentiate the company from competitors: "We realized that the market is pushing towards sustainability and corporate social responsibility. We scanned our competitors, and noticed that they were not fulfilling this demand. I think we are among the quickest catching this opportunity". Transparency, however, remains a value to protect: "Transparency is our reporting approach. We provide data, both positive and negative. Then, everyone can give his own interpretation of the data. A car can be vehicle or a trap that kills people on the highways. We are leader in our industry, we have cutting-edge manufacturing processes. Data regarding resource use and environmental impacts is not a secret. Those who have a good knowledge of our industry can take advantage of such data. We do our best to minimize our impacts and optimize the manufacturing processes. We pay a lot of attention on our human capital, we invest on training and motivation, and we invest on human resources in the long term. A set of values inspire our business, thus we do not fear negative disclosure". In view of that, the effort to increase the amount of disclosure is perceived as important: "With the second report, we increased the number of disclosed indicators by 20. Our reporting is going deeper: this year we intend to disclose more indicators". On the other hand, the commitment on transparency is not absolute, as economic considerations always play a central role: "We chose those indicators which were the easiest to report. We chose the indicators that required data we already had or which was relatively simple to obtain". This may lead to a less effective report, as "the measurements that are easiest to report are not always the most informative" (Chatterji \& Levine, 2006, p. 5). Report assurance too is considered as an avoidable extra-cost, even if assured reports respond to the demand for reliable and credible information, guaranteeing that the 
report truly represents a company's effort and achievements (KPMG/UvA, 2008): "We did not have a third party assuring the technical and numerical meaning of the indicators. We did not fear third parties assessment, but we decided to avoid this check because of costs. To tell the truth, we do not believe this element to be determinant".

On the side of report purposes and effects, Alfa considers CSD as a way to formalize and value the CSR initiatives: "In the past, we adopted many sustainable behaviors, but we were not aware of the value of these initiatives. Often, we even did not share the results with stakeholders, we did not communicate that our company was groundbreaking in specific fields. The reporting make our commitment visible. It provides us an organic and comprehensive framework, coordinating activities that otherwise would be isolated, and eventually we would lose the value behind them. In this manner, we can effectively plan our initiative and gather them within a unique global vision". Reporting activity is integrated in the business, as it helps strategic planning of CSR activities, increases internal communication and coordination, drives the partner selection along the supply-chain: "Data regarding human resources management, resources management, raw materials, energy, waste, processes efficiency are part of our management system. In the future, their importance will even increase, especially in partner selection processes. Along the supply chain, we will endorse and support those partners who will share these values with us".

In the end, CSD activity is allegedly not linked to a "direct commercial advantage", in the interviewee opinion, it brings mainly to cost increasing. Benefits are expected in the long run, as a yield on intangible assets, related to the voluntary nature of this activity: "In my opinion, companies should invest in this initiative even in the absence of immediate yields. It is difficult to gain on "soft", intangible, elements like this one, with no direct commercial advantage. We do not have an improvement in efficiency that allows us to lower prices. Frequently, this commitment leads only to cost increasing. However, it has to be considered in a frame of business supporting activities, something that pays in the long term without doubts. Being voluntary, this activity has the potentiality to provide a distinctive trait to reporting companies". The idea that companies should invest in CSD even in the absence of a clear return suggests that non-financial reporting is a practice pushed by external forces leveraging on the moderate-high score of power distance and high UAI: "The pressure on formalization is imported. In my opinion, it comes from the consumer market. Consumers want to be acknowledged of companies' values, and these values should guarantee social and environment respect".

\section{Conclusion}

This paper starts to shed light on SMEs corporate social disclosure practices, introducing an original approach based on Hofstede cultural dimensions model. CSD and CSR in general are a field dominated by large firms (Brown, de Jong, \& Levy, 2009), but SMEs too are engaging in social responsible activities, even if they prefer an informal commitment (Russo \& Tencati, 2009).

The stakeholder theory, which has been widely and successfully applied to describe CSR and CSD in large firms (Searcy, 2009), fails to provide a comprehensive theoretical framework to explain SME-CSR relationship (Russo \& Perrini, 2010), because SMEs are not "little big firms" (Tilley, 2000). Thus, other theories, such as the institutional and neo-institutional theories (DiMaggio \& Powell, 1983; Selznick, 1948; Scott, 2001), the social capital theory (Putnam, 2000) and the sustainable entrepreneurship theory (Schaltegger \& Wagner, 2011), are proposed. They are closer to SME idiosyncrasies, as they consider the relationship with institutions, local communities, and the central role of the entrepreneur.

The three theories share a common antecedent: culture. Hofstede (Hofstede, 1983) conceives culture as a collective mental programming, something which is learned through a socially constructed process. His studies show that societies' value system varies at national level, determining the way individuals cope with the relationship with authority, the relationship between the individual and the group, the social implications of having been born as a boy or a girl, the ways of dealing with uncertainty and risk. His model measures these four dimensions shaping national culture (individualism, power distance, masculinity, uncertainty avoidance), allowing to predict and motivate certain attitudes and behaviors within a nation. Italian scores on cultural dimensions show that institutional pressure might be the major driver for SMEs adopting CSD practices, consistently with other studies concerning CSR and the Italian context (Albareda, Tencati, Lozano, \& Perrini, 2006).

Through a single-case study methodology (Yin, 2003), based on a recorded semi-structured interview, I verify if this proposition is supported. The case analysis provides interesting results. The proposed company, Alfa, is a medium-sized business operating in the manufacture of crown corks, metal and plastic caps for the bottling industry. Alfa is a CSR-committed firm, conceiving social responsibility as a dimension strictly connected to its core business. However, the formalization of its commitment into practices, like non-financial reporting, is perceived as something extraneous, not belonging to company original culture. This is in line with the Italian dominant culture and findings 
by Russo and Tencati (2009). Interestingly, the main driver to adopt this practice is not institutional pressure, refusing the initial proposition of this study. Local and international authorities play a limited role in this process. Supply chain, market and business relationships, instead, seem to be the most important antecedent to formalize CSR commitment and disclose non-financial information. This finding is consistent with GRI point of view: "sustainability reporting is perceived to enhance SMEs position in the market, for instance allowing access to multinationals supply chains. Some multinationals request suppliers to report on sustainability." (Global Reporting Initiative, 2013, p. 17). Notwithstanding, commercial benefit are not indicated as an effect of report issuance, which is expected to pay in the long run because of the reputational value conveyed by its voluntary nature. The adoption of CSD seems to be imported from global markets and partners, leveraging on Italian moderate-high power distance, uncertainty avoidance and masculinity: Alfa follows a perceived global trend adopted by larger clients, engaging in a voluntary activity both to differentiate their performance and limit the fear of losing major clients. Indeed, transparency - which is the main value behind CSD - is considered important, but it is subordinated to cost saving logic.

Although the interesting findings emerging from this pilot case study, this paper can be a part of a more comprehensive research project. First, I intend to add more cases to increase the validity of the outcomes and allow comparison between different situations. Second, Hofstede cultural dimensions are best employed for cross-country comparison: it would be of interest to extend the analysis beyond national borders.

\section{Acknowledgement}

I thank the Editor of the International Journal of Business Administration and the anonymous reviewers for their comments and support. I thank Professor Angelo Russo for the support and advice. I thank the CSR Manager for his interview and the feedback. A special thank goes to Grazia Scioscia, the interpreter who reviewed the translation of the interview and checked the language of this work.

\section{References}

Aguinis, H., \& Glavas, A. (2012). What We Know and Don't Know About Corporate Social Responsability: A Review and Research Agenda. Journal of Management, 1-37.

Albareda, L., Tencati, A., Lozano, J., \& Perrini, F. (2006). The government's role in promoting corporate responsibility: a comparative analysis of Italy and UK from the relational state perspective. Corporate Governance, 6(4), 386-400. http://dx.doi.org/10.1108/14720700610689504

Brown, H., de Jong, M., \& Levy, D. (2009). Building institutions based on information disclosure: lessons from GRI's sustainability reporting. Journal of Cleaner Production, 571-580. http://dx.doi.org/10.1016/j.jclepro.2008.12.009

Campbell, J. (2006). Institutional Analysis and the Paradox of Corporate Social Responsibility. American Behavioral Scientist, 49(7), 925-938. http://dx.doi.org/10.1177/0002764205285172

Chatterji, A., \& Levine, D. (2006). Breaking Down the Wall of Codes: Evaluating Non-Financial Performance Measurement. California Management Review, 48(2), 1-23. http://dx.doi.org/10.2307/41166337

Chen, S., \& Bouvain, P. (2009). Is Corporate Responsibility Converging? A Comparison of Corporate Responsibility Reporting in the USA, UK, Australia and Germany. Journal of Business Ethics, 87, 299-317. http://dx.doi.org/10.1007/s10551-008-9794-0

Cohen, J., Pant, L., \& Sharp, D. (1996). A methodological on cross-cultural accounting ethics research. International Journal of Accounting, 31(1), 55-66. http://dx.doi.org/10.1016/S0020-7063(96)90013-8

Dahlsrud, A. (2008). How Corporate Social Responsibility Is Defined: An Analysis of 37 Definitions. Corporate Social Responsibility and Environmental Management, 15(1), 1-13. http://dx.doi.org/10.1002/csr.132

De Jong, M., Pieters, R., \& Fox, J. (2010). Reducing social desirability bias through item randomized response: An application to measure underreported desires'. Journal of Marketing Research, 47, 14-27. $\mathrm{http}: / / \mathrm{dx}$. doi.org/10.1509/jmkr.47.1.14

Del Baldo, M. (2012). Corporate social responsibility and corporate governance in Italian SMEs: the experience of some "spirited businesses". Journal of Management and Governance, 16(1), 1-36. http://dx.doi.org/10.1007/s10997-009-9127-4

DiMaggio, P., \& Powell, W. (1983). The Iron Cage Revisited: Insitutional Isomorphism and Collective Rationality in Organizationals Fields. American Sociological Review, 48(2), 147-160. http://dx.doi.org/10.2307/2095101

Dyllick, T., \& Hockerts, K. (2002). Beyond the business case for corporate sustainability. Business Strategy and the 
Environment, 130-141. http://dx.doi.org/10.1002/bse.323

Eisenhardt, K., \& Graebner, M. (2007). Theory Building from Cases: Opportunities and Challenges. Academy of Management Journal, 50(1), 25-32. http://dx.doi.org/10.5465/AMJ.2007.24160888

Elkington, J. (1997). Cannibal with forks. Oxford: Capstone publishing.

European Commission. (2013). The New SME Definition.

Foster, G. (1986). Financial Statement Analysis. Englewood Cliffs: Prentice-Hall.

Freeman, I., \& Hasnaoui, A. (2011). The Meaning of Corporate Social Responsibility: The Vision of Four Nations. Journal of Business Ethics, 100, 419-443. http://dx.doi.org/10.1007/s10551-010-0688-6

Freeman, R., \& Edward, R. (1984). Strategic Management: A stakeholder approach. Boston: Pitman.

Gjølberg, M. (2009). The Origin of Corporate Social Responsibility: Global Forces or National Legacies? Socio-Economic Review, 7(4), 605-637. http://dx.doi.org/10.1093/ser/mwp017

Global Reporting Initiative. (2011). GRI application levels.

Global Reporting Initiative. (2013). Carrots and Sticks. Sustainability reporting policies worldwide - today's best practices, tomorrow's trends.

Global Reporting Initiative. (2014, January). Disclosure Database. Tratto da Sustainability Disclosure Database. Retrieved from http://database.globalreporting.org/

Graafland, J., van de Ven, B., \& Stoffele, N. (2003). Strategies and Instruments for Organising CSR by Small and Large Businesses in the Netherlands. Journal of Business Ethics, 47(1), 45-60. http://dx.doi.org/10.1023/A:1026240912016

Gray, R. (1997). The practice of silent accounting. In S. Zadek, \& R. Evans (Eds.), Building Corporate Accountability. Emerging Practices in Social and Ethical Accounting, Auditing and Reporting (pp. 201-217). London: Earthscan.

Gray, R., Owen, D., \& Adams, C. (1996). Accounting and accountability. Changes and challenges in corporate social reporting and environmental reporting. Hemel Hempsteard, UK: Prentice Hall.

Habisc, A., Patelli, L., Pedrini, M., \& Schwartz, C. (2011). Different Talks with Different Folks: A Comparative Survey of Stakeholder Dialog in Germany, Italy, and the U.S. Journal of Business Ethics, 100(3), 381-404. http://dx.doi.org/10.1007/s10551-010-0686-8

Hall, P., \& Soskice, D. (2001). An Introduction to Varieties of Capitalism. In P. Hall, \& D. Soskice (Eds.), Varieties of Capitalism: The Institutional Foundations of Comparative Advantage (pp. 1-68). Oxford: Oxford University Press. http://dx.doi.org/10.1093/0199247757.001.0001

Ho, F., Wang, H., \& Vitell, S. (2012). A Global Analysis of Corporate Social Performance: The Effects of Cultural and Geographic Environments. Journal of Business Ethics, 107, 423-433. http://dx.doi.org/10.1007/s10551-011-1047-y

Hofstede, G. (1983). The Cultural Relativity of Organizational Practices and Theories. Journal of International Business Studies, 14(2), 75-89. http://dx.doi.org/10.1057/palgrave.jibs.8490867

Hofstede, G., Hofstede, G., \& Minkov, M. (2010). Cultures and Organizations: Software of the Mind. McGraw-Hill USA.

Hofstede, G., Neuijen, B., Ohayv, D., \& Sanders, G. (1990). Measuring Organizational Cultures: A Qualitative and Quantitative Study Across Twenty Cases. Administrative Science Quarterly, 35(2), 286-316. http://dx.doi.org/10.2307/2393392

House, R., Javidan, M., Hanges, P., \& Dorfman, P. (2002). Understanding cultures and implicit leadership theories around the globe: an introduction to project GLOBE. Journal of World Business, 37, 3-10. http://dx.doi.org/10.1016/S1090-9516(01)00069-4

Julien, P.-A. (1993). SMEs: Review and Perspectives. Paris: Economica.

Kavitha, W., \& Anita, P. (2011). Disclosures About CSR Practices: A Literature Review. The IUP Journal of Corporate Governance, $X(1), 45-55$.

Kolk, A. (2003). Trends in sustainability reporting by the fortune global 250. Business Strategy and the Environment, 12, 279-291. http://dx.doi.org/10.1002/bse.370 
KPMG. (2013). The KPMG Survey of Corporate Responsibility Reporting 2013.

KPMG/UvA. (2008). KPMG International survey of corporate sustainability reporting 2008. Amsterdam: KPMG Global Sustainability Services.

Lamberti, L., \& Lettieri, E. (2009). CSR Practices and Corporate Strategy: Evidence from a Longitudinal Case Study. Journal of Business Ethics, 87, 153-168. http://dx.doi.org/10.1007/s10551-008-9876-z

Langlois, C., \& Schlegelmich, B. (1990). Do Corporate Codes of Ethics Reflect National Character? Evidence from Europe and the United States. Journal of International Business Studies, 21(4), 519-539. http://dx.doi.org/10.1057/palgrave.jibs. 8490340

LeBlanc, B. (2012). Sustainability Rises On the CFO's "to-do" List. Financial Executive, 54-57.

Leonidou, L., Kvasova, O., Leonidou, C., \& Chari, S. (2013). Business Unethicality as an Impediment to Consumer Trust: The Moderating Role of Demographic and Cultural Characteristics. Journal of Business Ethics, 112(3), 397-415. http://dx.doi.org/10.1007/s10551-012-1267-9

Lepoutre, J., \& Heene, A. (2006). Investigating the Impact of Firm Size on Small Business Social Responsibility: A Critical Review. Journal of Business Ethics, 67, 257-273. http://dx.doi.org/10.1007/s10551-006-9183-5

Linnenluecke, M., \& Griffiths, A. (2010). Corporate sustainability and organizational culture. Journal of World Business, 45, 357-366. http://dx.doi.org/10.1016/j.jwb.2009.08.006

Logsdon, J., \& Wood, D. (2005). Global Business Citizenship and Voluntary Codes of Ethical Conduct. Journal of Business Ethics, 59, 55-67. http://dx.doi.org/10.1007/s10551-005-3411-2

Lubin, D., \& Esty, D. (2010). The sustainability imperative. Harvard business review, 2-9.

Matten, D., \& Moon, J. (2008). "Implicit" and "Explicit" CSR: A Conceptual Framework for a Comparative Understanding of Corporate Social Responsibility. Academy of Management Review, 33(2), 404-424. http://dx.doi.org/10.5465/AMR.2008.31193458

McWilliams, A., Siegel, D., \& Wright, P. (2006). Corporate Social Responsibility: Strategic Implications. Journal of Management Studies, 43, 1-18. http://dx.doi.org/10.1111/j.1467-6486.2006.00580.x

Meek, G., Roberts, C., \& Gray, S. (1995). Factors Influencing Voluntary Annual Report Disclosures by U.S., U.K. and Continental European Multinational Corporations. Journal of International Business Studies, 3rd Quarter, 555-572.

Michelon, G., \& Parbonetti, A. (2010). The effect of corporate governance on sustainability disclosure. Journal of Management and Governance, 16, 477-509. http://dx.doi.org/10.1007/s10997-010-9160-3

Mirvis, P., \& Googins, B. (2006). Stages of Corporate Citizenship. California Management Review, 48(2), 104-126. http://dx.doi.org/10.2307/41166340

O'Dwyer, B. (2011). The Case of Sustainability Assurance: Constructing a New Assurance Service. Contemporary Accounting Research, 28(4), 1230-1266. http://dx.doi.org/10.1111/j.1911-3846.2011.01108.x

Perego, P., \& Kolk, A. (2012). Multinationals' Accountability on Sustainability: The Evolution of Third-Party Assurance of Sustainability Reports. Journal of Business Ethics, 110, 173-190. http://dx.doi.org/10.1007/s10551-012-1420-5

Perrini, F. (2005). Building a European Portrait of Corporate Social Responsibility Reporting. European Management Journal, 23(6), 611-627. http://dx.doi.org/10.1016/j.emj.2005.10.008

Perrini, F. (2006). SMEs and CSR Theory: Evidence and Implications from an Italian Perspective. Journal of Business Ethics, 67(3), 305-316. http://dx.doi.org/10.1007/s10551-006-9186-2

Perrini, F., Russo, A., Tencati, A., \& Vurro, C. (2011). Deconstructing the Relationship between Corporate Social and Financial Performance. Journal of Business Ethics, 102, 59-76. http://dx.doi.org/10.1007/s10551-011-1194-1

Porter, M., \& Kramer, M. (2011). Creating Shared Value. Harvard business review.

Putnam, R. (2000). Bowling Alone: The Collapse and Revival of American Community. New York, NY: Simon and Schuster.

Ringov, D., \& Zollo, M. (2007). Corporate responsibility from a social-institutional perspective: The impact of national culture on corporate social performance. Corporate Governance, 7(4), 476-485. http://dx.doi.org/10.1108/14720700710820551 
Roca, L., \& Searcy, C. (2011). An analysis of indicators disclosed in corporate sustainability reports. Journal of Cleaner Production, 103-118.

Russo, A., \& Perrini, F. (2010). Investigating Stakeholder Theory and Social Capital: CSR in Large Firms and SMEs. Journal of Business Ethics, 91, 207-221. http://dx.doi.org/10.1007/s10551-009-0079-z

Russo, A., \& Tencati, A. (2009). Formal vs. Informal CSR Strategies: Evidence from Italian Micro, Small, Medium-sized, and Large Firms. Journal of Business Ethics, 85, 339-353. $\mathrm{http}: / / \mathrm{dx}$.doi.org/10.1007/s10551-008-9736-x

Schaltegger, S., \& Wagner, M. (2011). Sustainable Entrepreneurship and Sustainability innovation: categories and interactions. Business Strategy and the Environment, 222-237. http://dx.doi.org/10.1002/bse.682

Scott, W. (2001). Institutions and Organizations. Thousands Oaks, CA: Sage.

Searcy, C. (2009). Corporate sustainability performance measurement: Lessons from system of systems engineering. Proceedings of the 2009 IEEE international conference on systems, man, and cybernetics. San Antonio. http://dx.doi.org/10.1109/ICSMC.2009.5345999

Searcy, C. (2012). Corporate Sustainability Performance Measurement Systems: A Review and Research Agenda. Journal of Business Ethics, 107, 239-253. http://dx.doi.org/10.1007/s10551-011-1038-z

Selznick, P. (1948). Foundations of the Theory of Organizations. American Sociological Review, 13, 25-35. http://dx.doi.org/10.2307/2086752

Siggelkow, N. (2007). Persuasion with Case Studies. Academy of Management Journal, 50(1), 20-24. http://dx.doi.org/10.5465/AMJ.2007.24160882

Spence, C., \& Gray, R. (2007). Social and Environmental Reporting and the Business Case. London: ACCA Research Report no.98.

Spence, M., Gherib, J., \& Biwolé, V. (2011). Sustainable Entrepreneurship: Is Entrepreneurial Will Enough? A North-South Comparison. Journal of Business Ethics, 99, 335-367. http://dx.doi.org/10.1007/s10551-010-0656-1

Spiller, R. (2000). Ethical Business and Investment: A Model for Business and Society. Journal of Business Ethics 27, 149-160. http://dx.doi.org/10.1023/A:1006445915026

Sutantoputra, A. (2009). Social Disclosure rating system for assessing firms' CSR reports. Corporate Communications: An International Journal, 1(1), 34-48. http://dx.doi.org/10.1108/13563280910931063

The Hofstede Centre. (2013, January). National Culture Dimensions. Tratto da The Hofstede Centre. Retrieved from http://geert-hofstede.com/dimensions.html

Tilley, F. (2000). Small Firm Environmental Ethics: How Deep Do They Go? Business Ethics: European Review, 9(1), 31-41. http://dx.doi.org/10.1111/1467-8608.00167

Vitell, S., Paolillo, J., \& Thomas, J. (2003). The perceived role of ethics and social responsibility: A study of marketing professionals. Business Ethics Quarterly, 13(1), 63-86. http://dx.doi.org/10.5840/beq20031315

Watts, R., \& Zimmerman, J. (1986). Positive Accounting Theory. Englewood Cliffs: Prentice-Hall.

Yin, R. (2003). Case Study Research - Design and Methods (3rd ed.). Sage Publications.

\section{ANNEXES}

\section{The interview}

\section{Company presentation. Role of the interviewee. Description of the CSR area in the company}

"Alfa is part of an Italian industrial group. It is a family business: the ownership is Italian. In the last few years, Alfa has become a real multinational enterprise: It has 4 factories in 3 different continents: 2 of them in Italy, one in Egypt and the last one in Florida, United States. We work in the food packaging industry; in particular, we manufacture bottling closures, including crown corks, metal and plastic caps. In 2013, we made about 28 billion caps. Our production is mostly addressed to the international market. Indeed, more than the $50 \%$ of our products is sold outside Europe. Our commercial network is international and speaks more than 20 different languages. 
We created a formal CSR business function in 2012. The CSR project started in 2011 and developed in 2012. Currently, I am the manager for our CSR. Previously, I was the quality manager for the group, now only for a single facility. I also handle the customer service. I have been working in Alfa for many years, and this allowed me to be the best choice for managing company CSR. Our main goal is creating a CSR reporting system and organize all the activity related with the social responsibility that were not structured and formalized, even if carried out. We point out some improvement targets on which we want to concentrate resources and efforts. In general, we want to create an organic framework for activities that we carried out in the past, but in a spotted way."

\section{Why did you publish a non-financial report? Why did you choose the GRI framework?}

"We started a formal CSR program because we want to raise the awareness of what actually "corporate social responsibility" - a pretty vague definition indeed - means. We want to spread this awareness among our internal and external stakeholders, all those who interact with our company. We want them to know the features of our CSR, what we do in detail to be active and proactive in this field. Our main CSR target was to implement and standardize a reporting system, following the GRI Guidelines. We intend to renovate the commitment in the reporting activity each year and, through the collected data, we want to train our resources and diffuse in our company the knowledge regarding our social responsibility and performance. We want to promote our social responsibility commitment along the supply chain, from our suppliers to the final market, which is getting more and more receptive towards these topics. Manufacturing and trading world is gaining consciousness of CSR themes, and we are trying to embrace this philosophy structuring the activities that head in this direction.

Alfa is a classic $b 2 b$ company. Thus, for us is even more important trying to catch signals coming from the consumer market, which is not in direct contact with us. As a result, we have to be even more proactive, because we work on a double distance: our clients sell directly to consumers, but we do not. With our reporting, we provide a global vision of the aspects of social responsibility and sustainability that concern our business. Many initiatives have always been part of our company philosophy; other ones have developed during recent years and have not been sufficiently valued. In the past, we adopted many sustainable behaviors, but we were not aware of the value of these initiatives. Often, we even did not share the results with stakeholders, we did not communicate that our company was groundbreaking in specific fields.

The reporting makes our commitment visible. It provides us an organic and comprehensive framework, coordinating activities that otherwise would be isolated, and eventually we would lose the value behind them. In this manner, we can effectively plan our initiative and gather them within a unique global vision.

We chose the GRI framework because it is the most influential and legitimate. The GRI is one of the most important players in this field; it boasts a multidisciplinary international stakeholder network. We employed the last Guidelines available, the G3.1, and we are waiting for the new G4. Another important reason behind this choice is GRI's international uptake: we want that our reporting is acknowledged all over the world. However, our commitment includes other reporting initiatives, like the Carbon Disclosure Program."

\section{Reporting procedure}

"We invested in the reporting initiative because we felt that it was important for the consumers and in particular for our major clients. We work mostly with international clients, and we receive their inputs, coming directly from the consumer market. We realized that the market is pushing towards sustainability and corporate social responsibility. We scanned our competitors, and noticed that they were not fulfilling this demand. I think we are among the quickest catching this opportunity.

First, we had an internal check regarding how the report had to be structured. High managerial levels and the ownership too endorsed and stimulated this initiative. We gave the task to a business function that has relationship with each other function in the company. Indeed, the reporting activities require the involvement of the whole company. Data come from each managerial area: operations, marketing, human resources, and even sub-areas, such as safety, environmental management, resources training. After this preemptive stage, we chose the Guidelines to adopt. As I said before, we thought that the GRI provided the best framework.

Then, we identified a set of indicators that constituted our primary basis. With our first report, collecting data from 2009 to 2011, we received a B Application Level, checked by the GRI: it is an intermediate level of disclosure. With our second report, we increased the number of disclosed indicators, and we intend keep this trend in order to increase the sharing of sustainable information. During the first reporting period, an external consultancy helped us.

This was mainly because we wanted to save time and resources. The consultancy role lessened in the second reporting period. Our third report will be published without the help of consultancies." 


\section{Did the reporting procedure lead your organization to introduce new activities?}

"In general, I would say no. We already had a very strong commitment in social responsible activities. Some topics, linked to environmental sustainability and resource saving, were a central point in our business. The steel industry is strongly endowed with the ideas of restoring and recycling raw materials. We tried to gather all these activities, valuing them by sharing with stakeholders. Ethical values, enthused by true sustainability, inspire our business approach, they are native, inborn in it and people just follow them but are not aware of them. We recycle more than the $95 \%$ of our waste: this was not considered as a valuable information, but it is indeed.

Formalization and socialization of such data play an important role in terms of internal organization, towards employees and staff. Frequently, business functions do not communicate each other, even if we want to have an open structure. With the reporting activity, we have improved the communication within the organization: data flow in a positive and constructive way. The outcomes of the reporting activity are conveyed towards the stakeholder system, along the supply chain. In particular, our suppliers are large multinationals with specific needs - frequently linked to environment and sustainability. Logistics and shipping, for example, have a direct impact on environment. Investing in multimodal transport can determine orders from new clients. Some clients are willing to wait few more days more in order to avoid road transport.

Such information eventually reach the final customers: labels and markers identify bottles with reduced environmental impacts. Moreover, local and international authorities have a strong influence on our business. With our reporting initiative, we show a proactive and sensitive approach towards environmental impacts, workplace conditions, and commercial relationships.

During assessments, we can thus provide data in a clear and structured way, improving our corporate image and legitimacy. Local communities can benefit too. Volunteering and philanthropic initiatives raise the awareness that the company is interacting in a positive way in its context. We made the report available for download on our company website, as a way to guarantee the diffusion of the information. We translated it in four languages to eliminate any obstacle. Finally, in this CSR project, we also formalized our code of ethics."

\section{Does the report present negative disclosures? Do you fear that it would damage your image?}

"There are negative disclosures because they are part of the business. Manufacturing has environmental impacts. In the non-financial report and in the CDP as well, we provide sensitive information for our company. We are big steel consumers: we need about 60.000 tons of steel per year, the equivalent of an aircraft carrier. We need a lot of energy and raw materials. On the other hand, we have a huge production: we consume a lot because we manufacture a lot. What is important is to show that anyway we implemented some policies to reduce waste and negative spillover effects.

Transparency is our reporting approach. We provide data, both positive and negative. Then, everyone can give his own interpretation of the data. A car can be vehicle or a trap that kills people on the highways. We are leader in our industry, we have cutting-edge manufacturing processes. Data regarding resource use and environmental impacts are not a secret. Those who have a good knowledge of our industry can take advantage of such data. We do our best to minimize our impacts and optimize the manufacturing processes. We pay a lot of attention on our human capital, we invest on training and motivation, and we invest on human resources in the long term. A set of values inspire our business, thus we do not fear negative disclosure."

\section{On what basis did you choose the Application Level?}

"We chose those indicators which were the easiest to report. We chose the indicators that required data we already had or which was relatively simple to obtain. With the second report, we increased the number of disclosed indicators by 20. Our reporting is going deeper: this year we intend to disclose more indicators. We did not exclude indicators with negative data; we only chose the easiest to report."

\section{Did you assure your report?}

"We received the GRI check: they verified that indicators were truly disclosed following the Guidelines. We did not have a third party assuring the technical and numerical meaning of the indicators. We did not fear third parties assessment, but we decided to avoid this check because of costs. To tell the truth, we do not believe this element to be determinant."

\section{Do you consider the reporting activity integrated in your business or it has its own specific logic?}

"In my opinion, it is integrated in our business. Periodical reporting is only the final part of a business approach that will not change in the future. Social responsibility initiative are not carried out for reporting purposes, but because 
the company approaches its business in this way. Reporting is the formal cap, the tie on a well-made suit. I do not think that this system is detached from our company practices. CSR is the key for long-term company survival. We want to survive and grow: these topics will be more and more integrated in our business."

\section{Do you use reporting data in decision-making processes?}

"Yes, absolutely. Data regarding human resources management, resources management, raw materials, energy, waste, processes efficiency are part of our management system. In the future, their importance will even increase, especially in partner selection processes. Along the supply chain, we will endorse and support those partners who will share these values with us.

We will prefer those suppliers rather than the less proactive ones. In our DNA, we are sensitive over these topics. In the future, our challenge is to increase our commitment in the areas where we are weaker."

\section{What feedback have you received from external stakeholders?}

"Many suppliers from our supply chain approached CSR topics just like us: they are starting to formalize and report their existent commitment. Most of them come from Europe, so they are in an extremely competitive environment, where the level of attention to these themes is very high. On the other side, Far-East suppliers are starting to pay some attention to these dimensions and I think that in the following years there will be a major evolution in this sense. Our commercial partners and clients share a high level of responsiveness to CSR. They are in direct contact with the final market, which is demanding in this direction. Our commitment has certainly valued our company. Quantifying the returns of this effort in the short period is very difficult. Returns are expected in the long run, this is the winning vision of companies investing in the long term."

\section{Considering costs and benefits, what is your valuation of the reporting activity?}

"We will have returns in the long term. In my opinion, companies should invest in this initiative even in the absence of immediate yields. It is difficult to gain on "soft", intangible, elements like this one, with no direct commercial advantage. We do not have an improvement in efficiency that allows us to lower prices. Frequently, this commitment leads only to cost increasing. However, it has to be considered in a frame of business supporting activities, something that pays in the long term without doubts."

\section{Do you think that reporting should be voluntary?}

"Honestly, I cannot say. Being voluntary, this activity has the potentiality to provide a distinctive trait to reporting companies. This adds more value to voluntarily committing companies. Moreover, voluntariness guarantees the transparency and truthfulness of disclosed data. Compulsory reporting would increase firms' need to improve their image. In my opinion, there is more added value in the voluntariness. If it becomes compulsory, its spirit will be distorted. Reporting sustainability information is different from obeying the law. Law compliance is the basis, what goes beyond it is voluntary, and its voluntariness values it."

\section{Do you think that reporting regards only certain firms?}

"All firms can take advantage from reporting activity. It may be harder for small companies, because they have to allocate resources to this activity. The allocation of resources to reporting activity in an exclusive and continuative way is a major issue even in bigger firms, excluding mega companies with thousands of employees. Italian companies are small and medium, so they have problems devoting resources to reporting. However, I think that it is possible to strike a balance."

In your opinion, CSR and Sustainability are present in the Italian entrepreneurial culture or are "imported"?

"In Alfa there have always been a strong attention towards these topics, because of the industry and the ownership. National and European law is very strict on environmental and social issues. Firms working in less regulated markets are not sharing our spirit of social responsibility.

For us, these topics are part of our business philosophy. Instinctively, I would say that reporting comes from an international vision. In Italy, we are more pragmatic: we carry out things, but we do not formalize them. The pressure on formalization is imported. In my opinion, it comes from the consumer market. Consumers want to be acknowledged of companies' values, and these values should guarantee social and environment respect. Many CSR ideas are imported, but an important part of them has always been part of our entrepreneurial philoshopy." 